\title{
The Use of Herbal Products during Breastfeeding: A Study from a Public Italian Hospital
}

\author{
Vincenzo Aleandri ${ }^{1,2}$, Giuliano Bertazzoni ${ }^{1,3}$, Daniela Romanzi ${ }^{2}$, Giuseppe Vetrano ${ }^{2}$, Federico Durazzi ${ }^{4}$, Gabriela Mazzanti ${ }^{4}$ and Annabella
} Vitalone ${ }^{4^{*}}$

${ }^{1}$ Research Center on Evaluation of Quality in Medicine-CEQUAM, Sapienza University of Rome, Viale del Policlinico 155, 00161 Rome, Italy

${ }^{2}$ Department of Obstetric, Gynecology, and Urology, Sapienza University of Rome, Viale del Policlinico 155, 00161 Rome, Italy

${ }^{3}$ Emergency Department, Umberto I-Policlinico di Roma, Viale del Policlinico 155, 00161 Rome-Italy

${ }^{4}$ Department of Physiology and Pharmacology “V. Erspamer”, Sapienza University of Rome, Piazzale Aldo Moro 5, 00185, Rome, Italy

\begin{abstract}
Background: The use of herbal products is steadily increasing worldwide, especially by women, also during pregnancy and breastfeeding, even if safety data are lacking. Aim of this study was to estimate the prevalence of use and the attitude toward herbal remedies among women during breastfeeding, by an interview-based survey.
\end{abstract}

Methods: Participants were interviewed after receiving the informed consent, by a structured and validated questionnaire.

Results: Two hundred forty-four breastfeeding women completed the questionnaire. The majority of them were non-smokers and non-drinkers, whereas they were regular consumers of herbal products during breastfeeding (97\%). Medicinal plants most commonly used were sweet almond oil $(68 \%)$ and fennel $(37 \%)$. Herbal products were often associated with other prescription drugs $(89 \%)$. Five percent of women have experienced dermatological and gastrointestinal adverse reactions, potentially due to herbal products.

Conclusions: This study reports that nursing mothers are generally no smokers, avoid alcohol consumption, and they reduce the use of drugs to those really needed. At the main time, this study highlights that breastfeeding mothers have limited knowledge on the risk/benefit profile of plant-derived products. As data on the excretion of chemical components of herbal products and their metabolites in breast milk are lacking, it is generally better to avoid during breastfeeding the use "natural remedies" whose safety has not been well established.

Keywords: Herbal products; Breastfeeding women; Safety; Plantderived products

\section{Introduction}

Natural products, particularly plant-derived ones, are generally used to improve the sense of well-being as well as to treat minor illnesses, and their use is steadily increasing worldwide [1,2]. In particular, women of 25-34 years of age seem to be the major users of plant-derived products, also and especially during pregnancy and breastfeeding [3,4], because these products are perceived as risk-free and helpful for various physiopathological conditions [1]. Even if in the recent years the scientific interest for herbal products during pregnancy is increasing all over the world, the information available on their use by breastfeeding women is still lacking and almost missing. This lack of scientific data goes along with a lack of knowledge of pharmacokinetic data on most plant-derived products, so that the amount of them that diffuses into mother's milk is unforeseeable. In this perspective, various parameters (absorption, distribution, metabolism and excretion) should be cautiously evaluated. For example, the metabolic and excretory capacities of the babies increase in a directly manner with their age [5], whereas the absorption and distribution of a xenobiotic into the breast milk depends on its chemical and physical characteristics (acid or basic nature, lipophilicity, etc.), and on many other factors (e.g., milk composition, proteins binding) [5,6]. Therefore, the exposure to herbal products should be probably avoided, in absence of correct information. Hence, the aim of the present study is to evaluate the prevalence of use and the knowledge of the safety and efficacy of herbal products by breastfeeding women.

In our survey, herbal products are considered as all products (herbal dietary supplements, cosmetics, homeopathic remedies, and medicinal herbal-based products) containing an herbal substance. The latter is defined by the European Parliament as "all mainly whole, fragmented or cut plants, plant parts, algae, fungi, lichen in an unprocessed, usually dried form, but sometimes fresh". Moreover, from an herbal substance different herbal preparations (powdered herbal substances, tinctures, extracts, essential oils, etc.) can be made [7].

\section{Methods}

A mono-centric cross-sectional study was carried out at the Umberto I-Policlinico di Roma (an Italian public hospital in the centre of Italy). The interviews were carried out twice a week, from June 2012June 2013

Breastfeeding women were recruited for participation during their staying in the hospital, in the first few days after childbirth, and were random interviewed.

This study did not require ethical approval as it was an observational study. However, all study participants provided their informed consent, and the survey was also approved by the superintendent of

${ }^{*}$ Corresponding author: Annabella Vitalone, Department of Physiology and Pharmacology "V. Erspamer", Sapienza University of Rome, Piazzale Aldo Moro 5, 00185, Rome, Italy, Tel: +39-06-49912904; Fax: +39-06-49912480; E-mail: annabella.vitalone@uniroma1.it

Received July 05, 2014; Accepted August 22, 2014; Published August 29, 2014

Citation: Aleandri V, Bertazzoni G, Romanzi D, Vetrano G, Durazzi F, et al. (2014) The Use of Herbal Products during Breastfeeding: A Study from a Public Italian Hospital. J Food Process Technol 5: 354. doi:10.4172/2157-7110.1000354

Copyright: ( 2014 Aleandri V, et al. This is an open-access article distributed unde the terms of the Creative Commons Attribution License, which permits unrestricted use, distribution, and reproduction in any medium, provided the original author and source are credited. 
gynecology's ward of the Department of Obstetrics, Gynecology, and Urology, Sapienza University of Rome.

A structured questionnaire, that included descriptive (age, country of birth, level of study, work experience, etc.) and analytical (e.g., product used and reason of use, participant's knowledge and primary source of information on herbal products, use of other therapies, perspective of safety and efficacy) questions on herbal products, was utilized. The survey was planned and validated according to other language questionnaire $[8,9]$. The validation procedure was carried out by a panel of experts as reported by Lapi et al. [9]. The survey was administered in Italian language; a detailed sample of its translation is reported in Table 1.

What we intended for "herbal products", as previously stated, was explained to the interviewees before the administration of the questionnaire. All data were anonymously collected in a specific database, using Office Excel software. Skilled health personnel carried out each interview.

Statistical analysis included simple descriptive statistics such as mean and standard error for normally distributed data, and medians and ranges for non-normally distributed data.

\section{Results}

All breastfeeding women $(\mathrm{n}=244)$, that were contacted during their staying in the Umberto I - Policlinico hospital, gave their consent to the interview. In our study, as the breast milk is the first natural food for babies immediately after delivery $[10,11]$, we have considered as nursing women each woman who has mammary secretion of colostrum, transitional or mature milk [12]. Where specified (90.6\%; $n=221)$, they were $32( \pm 0.4)$ years old, Italian $(82.4 \% ; \mathrm{n}=182)$ and foreign $(17.6 \%$; $\mathrm{n}=39$ ) women. Italian women were mainly from the central Italy $(89 \% ; n=162)$, whereas the North $(1.7 \% ; n=3)$ and the South $(9.4 \%$; 17) of Italy were less represented. Among immigrant women, the most representative geographical areas were East of Europe (74.5\%; $n=29)$, Latin-American (15.4\%; $n=6)$, and Asia (10.2\%; $n=4)$. Nursing women had a medium level of education $(53.7 \% ; \mathrm{n}=131)$, and occupation $(24.2 \% ; \mathrm{n}=59)$ and $24.2 \%$ declared to be clerk. The majority of nursing women $(54.1 \% ; n=132)$ were non-smokers, or they stopped smoking during pregnancy $(35.2 \% ; \mathrm{n}=86)$. They were also no $(79.1 \% ; \mathrm{n}=186)$ or lightly $(19.1 \% ; n=45)$ consumers of alcoholic beverages. Only few breastfeeding women were smokers $(10.7 \%, \mathrm{n}=26)$ or heavy drinkers $(1.7 \%, n=4)$. A summary of the characteristics (e.g. life style, work experience) of the nursing women is presented in Table 2.

Among women surveyed, $79.8 \%(\mathrm{n}=190)$ had taken herbal products during their life and $97.3 \%(n=214)$ started to take these products also during pregnancy and breastfeeding. Only $20.2 \%(n=48)$ of women have never used herbal products in their life, and they did not use natural products neither during pregnancy, nor during breastfeeding $(2.7 \%, \mathrm{n}=6)$

The products most commonly used, their frequency of consumption and the duration of treatment are reported in Table 3. Breastfeeding women that used only multivitamin supplements were $1.4 \%(n=3)$.

Ninety-six percent $(n=235)$ of nursing women responded to the next part of the questionnaire, among them was also included one puerpera who could not breastfeed, but was taking various plantderived products (i.e., fennel and sweet almond oil).

Herbal remedies were often used in association between them (95.3\%, $\mathrm{n}=224)$ and with drugs $(89 \% ; \mathrm{n}=208)$, including steroids and thyroid hormones (55\%, $\mathrm{n}=114)$, antianemic $(45 \%, \mathrm{n}=94)$, and other gynecological medications $(43 \%, \mathrm{n}=90)$. The average number of herbal products taken in association by women $(\mathrm{n}=235)$ was about $2.47 \pm$ 0.07 (ranging from 1 to 7 products), whereas drugs were $1.96 \pm 0.06$ (ranging from 1 to 5 medicines) $(n=213)$

The most common reasons for using herbal products during lactation were considered as due to $(76.4 \%, \mathrm{n}=178)$ or partially dependent $(14.6 \%, n=34)$ on pregnancy or breastfeeding. Referring the aforementioned issues, in the multiple answers possibility, the following conditions were reported: breast milk stimulation and maintenance of lactation $(2.8 \% ; \mathrm{n}=6)$, dermatological conditions (85.8\%; $\mathrm{n}=193)$, gastrointestinal problems $(9.8 \% ; \mathrm{n}=22)$, psychological ailments (20.0\%: $n=45)$, and vascular troubles $(11.3 \% ; n=24)$. In particular, among dermatological problems, stretch marks $(85.8 \%$; $\mathrm{n}=182)$ and "preparation of nipples" for breastfeeding $(3.8 \%, \mathrm{n}=8)$ were the most recorded. Regarding psychological conditions, anxiety $(13.7 \% ; \mathrm{n}=29)$ and insomnia $(1.9 \%, \mathrm{n}=4)$ were the most common. As regards discomforts related to gastrointestinal conditions, constipation $(3.3 \%, \mathrm{n}=7)$ and dyspepsia $(4.2 \%, \mathrm{n}=9)$ were frequently reported. Finally, among vascular troubles, conditions as varices $(7.5 \%, \mathrm{n}=16)$ and heavy legs sensation $(2.4 \%, \mathrm{n}=5)$ were recurrent.

The interviewed women (responders=235) learned about herbal products from the advices of variety of sources that included the following: gynecologist $(44 \% ; n=103)$, herbalist $(40 \% ; n=94)$, pharmacist $(29 \% ; n=68)$, general practitioner $(23 \% ; n=55)$, friends $(15 \% ; n=34)$, pediatrician $(13 \% ; n=30)$, personal experience $(10 \%$; $\mathrm{n}=24)$, and Internet websites $(9 \% ; \mathrm{n}=21)$. Purchase of various plantderived products occurred primarily in pharmacy $(66 \% ; n=154)$, herbalist's shops $(39 \% ; n=90)$, supermarket $(20 \% ; n=47)$, perfumery $(13.7 \%, n=32)$, Internet $(0.9 \% ; n=2)$ and catalogues $(0.9 \% ; n=2)$.

Breastfeeding women considered as the unsafe period in taking herbal products during pregnancy the following: first trimester $15 \%$ $(n=35)$, all over the pregnancy period $3 \%(n=7)$, never $75 \%(n=175)$, don't know 7\% $(\mathrm{n}=17)$. On the other hand, drugs were considered as dangerous during the first trimester by $36 \%(n=83)$, all over the pregnancy period by $53 \%(n=123)$, never by $2 \%(n=5)$, and don't know by $9 \%(n=21)$ of the interviewed.

The opinion of breastfeeding women on the safety and efficacy of herbal remedies versus pharmaceutical products is reported in Figures $1 \mathrm{~A}$ and $1 \mathrm{~B}$, respectively.

Finally, $5.1 \%(n=12)$ of breastfeeding women experienced adverse dermatological reactions $(n=8)$ such as erythema, dermatitis, itching, and burning sensation, generally associated to the use of sweet almond oil $(\mathrm{n}=5)$, vanilla cream $(\mathrm{n}=1)$, and cosmetics containing various associations of herbal ingredients, including rice oil (Oryza sativa), pea extract (Pisum sativum), sunflower oil (Helianthus annuus), castor oil, etc. $(n=2)$. Gastrointestinal reactions (i.e. heartburn, vomit, constipation; $\mathrm{n}=4)$, after using multivitamin supplements $(\mathrm{n}=3)$ and herbal derived product $(n=1)$ were also reported. In particular, a case of constipation was reported in an infant of 10 weeks, whose mother had been taking a product containing numerous medicinal plants, including coriander (Coriandrum sativum), ginger (Zingiber officinalis), cumin (Cuminum cyminum), chicory (Cichorium intybus), fennel (Foeniculum vulgare), althaea (Althaea officinalis).

\section{Discussion}

To the best of our knowledge and according to a search on PubMed website-terms that were searched on January 2014, without any 
Citation: Aleandri V, Bertazzoni G, Romanzi D, Vetrano G, Durazzi F, et al. (2014) The Use of Herbal Products during Breastfeeding: A Study from a Public Italian Hospital. J Food Process Technol 5: 354. doi:10.4172/2157-7110.1000354

\begin{tabular}{|c|c|}
\hline Personal data & $\begin{array}{ll}\text { Age: } & \text { Nationality: } \\
\text { Level of education: } & \text { Profession: } \\
\text { Week of lactation: } & \\
\text { Previous pregnancies: } & \\
\text { - Yes } & \\
\text { - If yes, how many? } & \text { No }\end{array}$ \\
\hline Lifestyle & 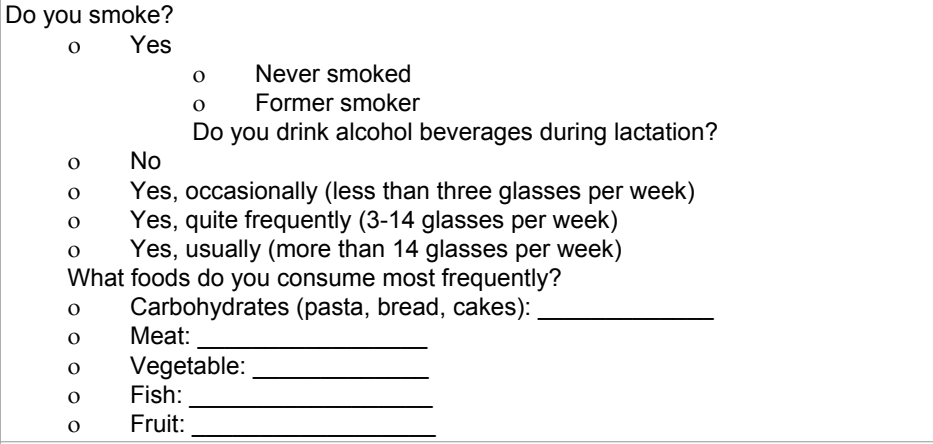 \\
\hline $\begin{array}{l}\text { Use of herbal products } \\
\text { during life }\end{array}$ & $\begin{array}{l}\text { Have you ever used herbal products? } \\
\begin{array}{cc}\text { o } & \text { Yes } \\
\text { o } & \text { No }\end{array}\end{array}$ \\
\hline $\begin{array}{l}\text { Use of herbal products } \\
\text { during pregnancy/lactation }\end{array}$ & 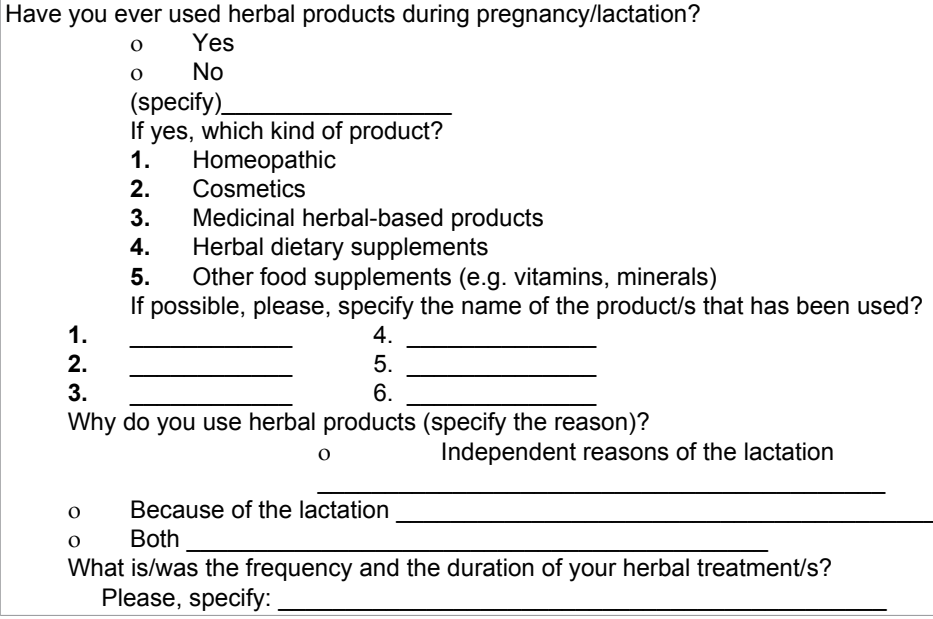 \\
\hline
\end{tabular}

Table 1: Sample of questionnaire, administered to breastfeeding women by health professionals

\section{Opinion of breastfeeding women on natural products}
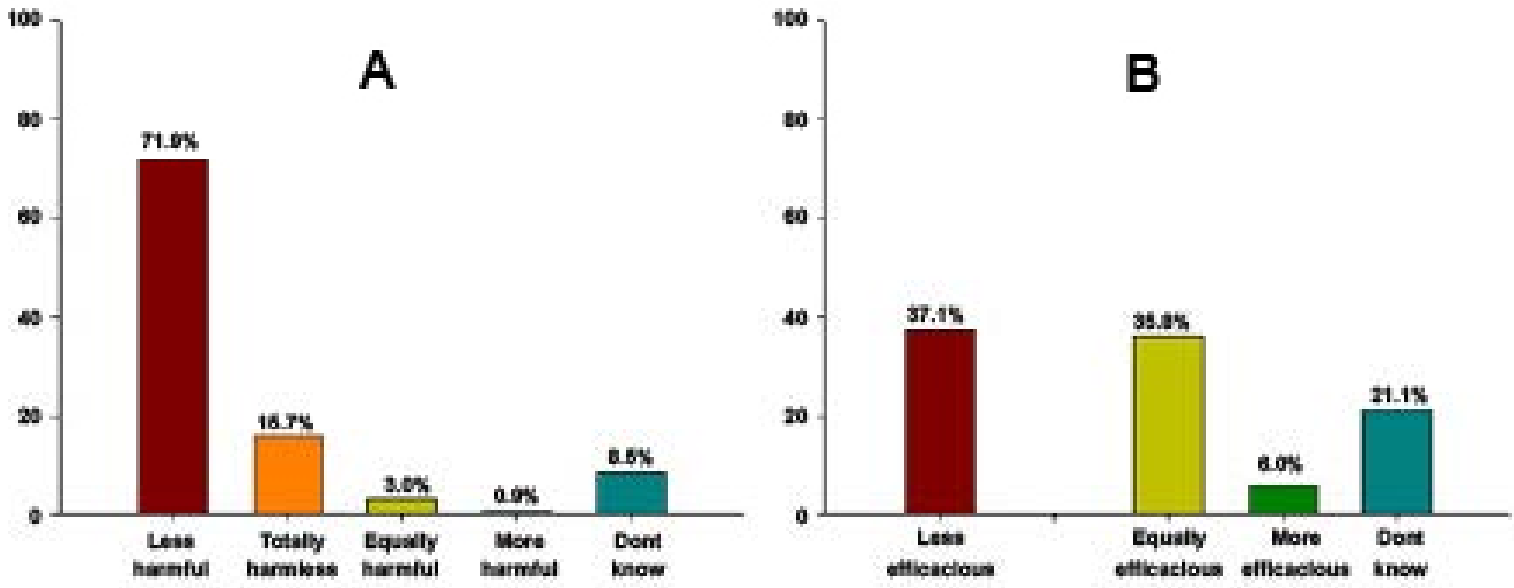

Figure 1: Nursing women's opinion about safety (A) and efficacy (B) of consuming herbal products during breastfeeding, compared to pharmaceutical products 
Citation: Aleandri V, Bertazzoni G, Romanzi D, Vetrano G, Durazzi F, et al. (2014) The Use of Herbal Products during Breastfeeding: A Study from a Public Italian Hospital. J Food Process Technol 5: 354. doi:10.4172/2157-7110.1000354

\begin{tabular}{|c|c|}
\hline Characteristics & $\%(n)$ \\
\hline Nationality & $\begin{array}{ccc}\text { Italian: } 82.4 \%(182) & \\
\bullet & \text { Northern } & 1.7 \%(3) \\
\text { - } & \text { Central } \quad 89.0 \%(162) \\
\text { - } & \text { Southern } \quad 9.4 \%(17) \\
\text { - } & \text { Foreigners: } 17.6 \%(39)\end{array}$ \\
\hline Parity & $\begin{array}{c}\text { Primiparous: } 50.4 \%(123 / 244) \\
\text { - } \quad \text { previous pregnancy: } 61.2 \%(74 / 121) \\
\text { - } \quad \text { previous pregnancies } 26.4 \%(32 / 121) \\
\text { - } \quad \text { previous pregnancies } 5.8 \%(7 / 121) \\
\text { - } \quad>3 \text { previous pregnancies: } 6.6 \%(8 / 121)\end{array}$ \\
\hline $\begin{array}{l}\text { Level of educa- } \\
\text { tion }\end{array}$ & $\begin{array}{l}\text { Primary/secondary school: } 18.4 \%(45) \\
\text { High school: } 53.7 \%(131) \\
\text { Degree: } 27.9 \%(68)\end{array}$ \\
\hline Occupation & $\begin{array}{l}\text { Clerk: } 24.2 \%(59) \\
\text { Housewife: } 19.7 \%(48) \\
\text { Teacher: } 7.0 \%(17) \\
\text { Worker: } 4.5 \%(11) \\
\text { Saleswoman: } 4.5 \% 11) \\
\text { Beautician: } 2.9 \%(7) \\
\text { Shopkeeper: } 2.5 \%(6) \\
\text { Nurse: } 2.5 \%(6) \\
\text { Social worker:2.0\% (5) } \\
\text { Student: } 2.0 \%(5)\end{array}$ \\
\hline Favorite food & $\begin{array}{l}\text { Carbohydrates (pasta, bread, etc.): } 34.1 \%(79) \\
\text { Meat (beef, white meat, etc.): } 22.8 \%(53) \\
\text { Vegetable (salad, spinach, etc.): } 22.0 \%(51) \\
\text { Fruit (orange, apple, etc.): } 15.9 \%(37) \\
\text { Fish (shrimp, tuna, etc.): } 3.4 \%(8) \\
\text { Other (milk, dairy products, etc.): } 1.7 \% \text { (4) }\end{array}$ \\
\hline Smoking & $\begin{array}{l}\text { Current smoker: } 10.7 \%(26) \\
\text { Never smoker: } 54.1 \%(132) \\
\text { Previous smoker: } 35.2 \%(86)\end{array}$ \\
\hline Alcohol use & $\begin{array}{l}\text { No, never: } 79.1 \%(186) \\
\text { Yes, occasionally (less than three glasses per week) : } 19.1 \% \\
(45) \\
\text { Yes, quite frequently ( } 3-14 \text { glasses of alcohol /week): } 1.7 \% \text { (4) }\end{array}$ \\
\hline
\end{tabular}

Table 2: Descriptive characteristics of breastfeeding women $(n=244)$ limit of language, were the following: "botanicals and breastfeeding" "herbal products and breastfeeding"-this is one of the few studies that examined personal use, knowledge of safety and efficacy of herbal products among breastfeeding women.

Limitation of the study is that this a mono-centric study that involved breastfeeding women from one geographic location (Rome, Italy), however data were obtained from the Umberto I-Policlinico of Rome, which is the biggest public hospital in Italy, and even one of the largest in Europe [13].

The analyzed population, despite their medium sociocultural level, appeared to be conscious to use drugs only when necessary and aware of the importance of a proper diet, during breastfeeding. This fact is important, because of the recent evidence indicating that breastfed infants, as exposed to a variety of flavors by mother's milk, have a greater acceptability of new food during their weaning period, and are less inclined to develop chronic diseases [14]. Of note is that nursing women were regular users of a variety of plant-derived products; even those who had never used herbal products during their life, began to take them (almost every day) during pregnancy and continued throughout breastfeeding. Moreover, breastfeeding women often associated herbal remedies between them, and/or with drugs. This should be avoided, considering the possibility of pharmacological interactions between different therapies that makes the final effect of the association totally unforeseeable $[15,16]$.

Breastfeeding women considered plant-derived supplements as useful, without taking into account the possibility of adverse outcome for them and/or their baby, and considered herbal products as less dangerous than drugs, so having a poor knowledge of the risk/ benefit profile of botanicals. These beliefs have also been reported in other studies carried out in pregnant and breastfeeding women $[3,17,18]$. Paradoxically, interviewed women used herbal products, even if considered them less efficacious than pharmaceutical products. Compared to what happens in other countries, where family and friends are the most cited source of information about botanicals [19], in our study, participant's primary source of advice was gynecologists. However, while herbalists and pharmacists receive academic training courses on botanicals, other health practitioners (including

\begin{tabular}{|c|c|c|c|}
\hline Product used \% (n) & Frequency of use $\%(n)$ & $\begin{array}{l}\text { Duration of use } \\
\text { (days } \pm \mathrm{SE} \text { ) }\end{array}$ & Most representative ingredients \\
\hline Cosmetics containing plants 93.6 (218) & $\begin{array}{l}\text { Daily } 95.0(191) \\
\text { Twice a week } 2.5(5) \\
\text { Once a week } 2.5(5)\end{array}$ & $199.0 \pm 5.4$ & $\begin{array}{l}\text { - Almond oil }(68.3 \% ; n=149) \text {; } \\
\text { - Multi-herbal ingredients, including rice oil in association with peas extract, } \\
\text { sunflower, castor oil }(29.8 \% ; n=65) \text {; } \\
\text { - Calendula }(2.3 \% ; n=5) \\
\text { - Aloe gel }(1.4 \% ; n=3) \\
\text { - Others }(5.1 \% ; n=11)\end{array}$ \\
\hline Food supplements 91.4 (213) & $\begin{array}{l}\text { Daily } 98.1(154) \\
\text { Twice a week } 1.9 \text { (3) }\end{array}$ & $184.6 \pm 80.7$ & $\begin{array}{l}\text { - Multivitamin supplements }(54.9 \% ; n=117 \text { ) } \\
\text { - Others (folic acid, iron, etc. - } 80.8, n=172 \text { ) }\end{array}$ \\
\hline Herbal dietary supplements 36.9 (86) & $\begin{array}{l}\text { Daily } 81.9(59) \\
\text { Twice a week } 11.1(8) \\
\text { Once a week } 6.9(5)\end{array}$ & $198.2 \pm 12.6$ & $\begin{array}{l}\text { - Fennel }(37.2 \% ; n=32) \\
\text { - Licorice }(5.8 \% ; n=5) ; \\
\text { - Fenugreek }(3.5 \% ; n=3) \\
\text { - Green tea }(3.5 \% ; n=3) \\
\text { - Others (unspecified multiple-ingredients herbal teas - } 31.4 \% ; n=27 ; \text { propolis } \\
41.3 \% ; n=19,)\end{array}$ \\
\hline Homeopathic medicines $10.3(24)$ & Daily $100(9)$ & $82.8 \pm 38.0$ & $\begin{array}{l}\text { - Arnica }(17 \% ; n=4) \\
\text { - Multi-ingredient syrup }(8.3 \% ; n=2)\end{array}$ \\
\hline Herbal derived drugs 11.7 (14) & $\begin{array}{l}\text { Daily } 60.0(3) \\
\text { Twice a week } 20.0(1) \\
\text { Once a week } 20.0(1)\end{array}$ & $122.8 \pm 58.4$ & $\begin{array}{l}\text { - Valerian }(28.6 \%, n=4) \\
\text { - Aloe juice }(7.1 \% ; n=1) \\
\text { - Silymarin (from milk thistle) }(14.3 \% ; n=2)\end{array}$ \\
\hline
\end{tabular}

Table 3: Characteristics of plant-derived products used by breastfeeding women. Data are reported as percentage (\%) and number of respondents ( $\mathrm{n}$ ), taking into account that the interviewed women had a multiple answer possibility 
gynecologists) usually do not receive any professional education on herbal remedies, at least in Italy. The comforting aspect, despite the e-trade of botanicals is widespread, is that the nursing Italian women appeared to prefer pharmacies, as their favorite source of purchasing.

In our study, most of women reported no side effects, with the exception of dermatological and gastrointestinal reactions associated with cosmetics and herbal supplements. The first category is considered as safe, even if few adverse reactions due to their herbal composition are reported $[3,15,20]$. Some concerns raised from the daily application of almond oil to the abdomen of pregnant women, because it was associated with preterm birth [3]. The authors have hypothesized that the association between almond oil and shortening of gestation could be due to a premature contractions by a chronic mechanical stimulation of myometrium and/or to an uterotonic effect of some almond oil compounds (e.g., fatty acids), which could target the myometrium [3]. This event, although unusual and not related with lactation, should be kept in mind because if almond oil can reach the myometrium, may also be delivered to the infant through breast milk.

The use of other herbal-based cosmetics has been reported, including those containing calendula and aloe. Even if both plants appear as safe in the common practice, eczema and ocular irritations are reported $[15,21]$, as well as contact dermatitis and oral mucositis after the topical application of aloe [22]. Consequently, they should be contraindicated in hypersensitive patients [16]

Regarding herbal supplements, safety data were not discussed in the clinical studies identified for lactation [23]. However, several reactions have been recently reported, making some medicinal plants unsuitable for their use during lactation and other specific conditions $[19,23,24]$. In our survey, breastfeeding women reported the use of milk thistle and fenugreek (usually in association), as galactogogues, although their effects and the dose necessary to obtain an increase of breast milk production should be further evaluated $[23,25]$. Both herbs have been suspected to increase the risk of bleeding, and it is suggested that they should be discontinued at least two weeks before any surgical procedure [26]. Then, their use shortly before the childbirth is not safe. In addition, fenugreek could induce hypoglycemia and gastrointestinal upsets and should be used cautiously in patients taking medications that may interfere at the same pharmacological levels [21,27].

In our study, additional concerns arise from other medicinal plants used by nursing women (e.g. fennel, licorice, aloe). Foeniculum vulgare and Glycirrizza glabra have been used as herbal dietary supplements, whereas Aloe vera has been taken as non-prescription medicine. For these plant-derived products, several adverse reactions have been reported. In particular, fennel may cause contact dermatitis, and an increase of estrogen levels [16]. Its long term use has been associated with the onset of premature thelarche in one female infant and three female children, where an increase of 15-20 fold of serum estradiol levels, and a case of vaginal discharge were found [28]. This estrogenic effect (ascribed to the anethole content) could also induce a suppression of lactation in breastfeeding mothers [28]. Noteworthy is that, in our survey, one of the fennel consumers could not breastfeed; however a definitive conclusion cannot be drawn from this case. As regards licorice, some evidences suggest that its regular intake is associated with adverse manifestation, including cardiovascular reactions [20], abortion and preterm labour [3]. In some cases, however, other drugs (e.g., antinflammatory, antihypertensives) taken in association with licorice could be involved in the adverse outcome [20]. Moreover, of concern are association of licorice and fennel with other medicinal plants, that have been reported to induce lethargy, hypotonia, and emesis in two neonates of breastfeeding women consuming a large volumes of this herbal tea mixture [29]. With regard to the use of aloe as a laxative medicine, it should be kept in mind that its use is not recommended in children under 12 years of age and, according to European Medicine Agency, during breastfeeding, "as there are insufficient data on the excretion of metabolites in breast milk", but it is hypotized that some its metabolites pass in small amounts [30]. Finally, the constipation reported in an infant of 10 weeks, whose mother had been taking a mixture of medicinal plants is not scientifically explainable, because of the complexity of the product [20]. Moreover, as it is unknown if plant ingredients are excreted in human breast milk, their use during lactation is not recommended [31-33]. Noteworthy is that for all of the mentioned products in our study, no information is available on their quality and this it should be taken in mind before drawing definitive conclusions on the safety of "natural" products.

In this study, taking into consideration the widespread use of botanical agents, in relation to the relatively small number of adverse reactions due to them, it seems that the incidence of adverse effects is low. However, it is clear that the implementation of the Phytovigilance system can further improve our knowledge on the safety of botanicals. In accordance to the Motherisk Program, to achieve a conclusion on this topic there is a need for future research [34]. Till then, these products should be probably contraindicated because, even if we do not know if they are dangerous, we are not sure of their safety [35].

\section{Conclusions}

This study highlights the need to provide comprehensive information on the use of plant-derived products to nursing women. In order to give them a qualified advice, the health care staff (e.g., general practitioners, gynecologists, pharmacists, nurses, pediatricians, and herbalists) should know how to access unbiased and reliable information sources, and should always update their knowledge on herbal products. This study could be of a wide audience interest and could contribute to the international knowledge, as the existing international research base on plant-derived products used during breastfeeding is still lacking.

\section{Acknowledgements}

Authors want to thank the Enrico and Enrica Sovena Foundation for having supported this study and are also are grateful to Dr Francesca Menniti-Ippolito and Dr Marco Massari for their professional assistance in the statistical analysis. Last, but not least, all co-authors want to thank all women that have accepted to answer to the questionnaire of this survey.

\section{Conflict of Interest}

All authors declare that no conflicts of financial and commercial interest exist.

\section{References}

1. Bishop JL, Northstone K, Green JR, Thompson EA (2011) The use of Complementary and Alternative Medicine in pregnancy: data from the Avon Longitudinal Study of Parents and Children (ALSPAC). See comment in PubMed Commons below Complement Ther Med 19: 303-310.

2. Van den Berg SJ, Serra-Majem L, Coppens P, Rietjens IM (2011) Safety assessment of plant food supplements (PFS). See comment in PubMed Commons below Food Funct 2: 760-768.

3. Facchinetti F, Pedrielli G, Benoni G, Joppi M, Verlato G, et al. (2012) Herba supplements in pregnancy: unexpected results from a multicentre study. See comment in PubMed Commons below Hum Reprod 27: 3161-3167. 
Citation: Aleandri V, Bertazzoni G, Romanzi D, Vetrano G, Durazzi F, et al. (2014) The Use of Herbal Products during Breastfeeding: A Study from a Public Italian Hospital. J Food Process Technol 5: 354. doi:10.4172/2157-7110.1000354

4. Hall HG, Griffiths DL, McKenna LG (2011) The use of complementary and alternative medicine by pregnant women: a literature review. See comment in PubMed Commons below Midwifery 27: 817-824.

5. Bologna E (2004) Farmaci e allattamento: Elementi di farmacologia clinica pe la pratica medica. Bologna E (ed) Edizioni Medico Scientifiche Internazionali (EMSI), Rome, Italy.

6. Mattison D, Zajicek A (2006) Gaps in knowledge in treating pregnant women See comment in PubMed Commons below Gend Med 3: 169-182.

7. The European Parliament (2004) Directive 2004/24/EC of the European Parliament and of the Council amending. As regards traditional herbal medicinal products, Directive 2001/83/EC on the Community code relating to medicinal products for human use.

8. Boynton PM, Greenhalgh T (2004) Selecting, designing, and developing your questionnaire. See comment in PubMed Commons below BMJ 328: 1312 1315.

9. Lapi F1, Vannacci A, Moschini M, Cipollini F, Morsuillo M, et al. (2010) Use Attitudes and Knowledge of Complementary and Alternative Drugs (CADs) Among Pregnant Women: a Preliminary Survey in Tuscany. See comment in PubMed Commons below Evid Based Complement Alternat Med 7: 477-486.

10. World Health Organization (WHO) (2014) Exclusive breastfeeding

11. Ministero della Salute (2013) Allattamento

12. Nice FJ, Luo AC (2012) Medications and breast-feeding: Current concepts. See comment in PubMed Commons below J Am Pharm Assoc (2003) 52: 86-94.

13. Cusmai E (2009) Ecco gli ospedali migliori d'Italia. II Giornale.

14. Scott JA, Chih TY, Oddy WH (2012) Food variety at 2 years of age is related to duration of breastfeeding. See comment in PubMed Commons below Nutrients 4: 1464-1474.

15. Aberer W (2008) Contact allergy and medicinal herbs. See comment in PubMed Commons below J Dtsch Dermatol Ges 6: 15-24.

16. Singh D, Gupta R, Saraf SA (2012) Herbs-are they safe enough? an overview. See comment in PubMed Commons below Crit Rev Food Sci Nutr 52: 876-898.

17. Holst L, Wright D, Haavik S, Nordeng $H(2011)$ Safety and efficacy of herbal remedies in obstetrics-review and clinical implications. See comment in PubMed Commons below Midwifery 27: 80-86.

18. Sim TF, Sherriff J, Hattingh HL, Parsons R, Tee LB1 (2013) The use of herbal medicines during breastfeeding: a population-based survey in Western Australia. See comment in PubMed Commons below BMC Complement Altern Med 13: 317

19. Holst L, Wright $D$, Haavik S, Nordeng $H(2009)$ The use and the user of herba remedies during pregnancy. See comment in PubMed Commons below J Altern Complement Med 15: 787-792.

20. Cuzzolin L, Zaffani S, Benoni G (2006) Safety implications regarding use of phytomedicines. See comment in PubMed Commons below Eur J Clin Pharmacol 62: 37-42.
21. Andersen FA, Bergfeld WF, Belsito DV, Hill RA, Klaassen CD (2010) Final report of the Cosmetic Ingredient Review Expert Panel amended safety assessment of Calendula officinalis-derived cosmetic ingredients. Int J Toxicol 29: 221S-243.

22. Chinnusamy K, Nandagopal T, Nagaraj K, Sridharan S (2008) Aloe vera induced oral mucositis: a case report. The Internet Journal of Pediatrics and Neonatology.

23. Zapantis A, Steinberg JG, Schilit L (2012) Use of herbals as galactagogues. See comment in PubMed Commons below J Pharm Pract 25: 222-231.

24. Menniti-Ippolito F, Mazzanti G, Vitalone A, Firenzuoli F, Santuccio C (2008) Surveillance of suspected adverse reactions to natural health products: the case of propolis. See comment in PubMed Commons below Drug Saf 31: 419423.

25. Zuppa AA, Sindico P, Orchi C, Carducci C, Cardiello V, et al. (2010) Safety and efficacy of galactogogues: substances that induce, maintain and increase breast milk production. See comment in PubMed Commons below J Pharm Pharm Sci 13: 162-174.

26. Onyeka TC, Ezike HA, Nwoke OM, Onyia EA, Onuorah EC, et al. (2012) Herbal medicine: a survey of use in Nigerian presurgical patients booked for ambulatory anaesthesia. See comment in PubMed Commons below BMC Complement Altern Med 12: 130.

27. Tiran D (2003) The use of fenugreek for breast feeding women. See comment in PubMed Commons below Complement Ther Nurs Midwifery 9: 155-156.

28. Turkyilmaz Z, Karabulut R, Sonmez K, Can BaÅŸaklar A (2008) A striking and frequent cause of premature thelarche in children: Foeniculum vulgare. See comment in PubMed Commons below J Pediatr Surg 43: 2109-2111.

29. Rosti L, Nardini A, Bettinelli ME, Rosti D (1994) Toxic effects of a herbal tea mixture in two newborns. See comment in PubMed Commons below Acta Paediatr 83: 683

30. European Medicines Agency website (2006) Community Herbal Monograph on Aloe barbadensis Miller and on Aloe (various species, mainly Aloe ferox Miller and its hybrids). Doc Ref EMEA/HMPC/76310/2006 Corrigendum.

31. European Medicines Agency website (2009) Community herbal monograph on Althaea officinalis L., radix. Doc. Ref.: EMEA/HMPC/98717/2008.

32. European Medicines Agency website (2007) Community herbal monograph on Foeniculum vulgare Miller subsp. vulgare var. vulgare, aetheroleum. Doc. Ref EMEA/HMPC/263292/2006.

33. European Medicines Agency website (2013) Community herbal monograph on Cichorium intybus L., radix. Doc. Ref.: EMA/HMPC/121816/2010.

34. Koren G, Dugoua JJ, Magee L, Vohra S, Matsui D, et al. (2008) MotherNature: establishing a Canadian research network for natural health products (NHPs) during pregnancy and lactation. See comment in PubMed Commons below Altern Complement Med 14: 369-372.

35. Ernst E (2002) Herbal medicinal products during pregnancy? See comment in PubMed Commons below Phytomedicine 9: 352-354. 